\title{
Knowledge and practice of immediate new-born care among midwives in central zone public health facilities, Tigray, Ethiopia: cross sectional study
}

\author{
Tesfay Tsegay Gebru*, Rajalakshmi Murugan², Alem Gebremariam Abrha ${ }^{3}$ and Mekonnen Haftom Goyteom ${ }^{1}$
}

\begin{abstract}
Objective: The objective of this study was to assess knowledge and practice of immediate new-born care among midwives in central zone public health facilities Tigray region, 2016.

Results: The mean age of the study participants was 34.1 years. Majority of the participants (83\%) were diploma midwives. The score of knowledge of participants on immediate new-born care was $17.7 \%$ good and $25.2 \%$ poor. More than half (52.4\%) of midwives practiced immediate new-born care. Midwives working in health center have $82 \%$ lower odds of new-born care compared to those working in hospital $(p=0.000, O R=0.18(0.07,0.43)$.
\end{abstract}

Keywords: Knowledge, Practice, Immediate new-born care, Tigray, Ethiopia

\section{Introduction}

New-born is completely tiny and powerless, and dependent on other [1]. Crying after delivery is an indicative of establishing active breathing [2]. Babies die after birth because they have difficulty of adapting to extra uterine life [3]. There are 20 countries with the highest neonatal mortality rates worldwide, out of this 16 are found in Africa including Ethiopia. One in 11 children in subSaharan Africa dies before celebrating their fifth years [4-6].

Even-though becoming new-born is not a disease, huge numbers of new-borns are dying immediately after birth [3]. Evidences showed that the day of birth is the riskiest time that is a child is 500 times more likely to die in the first day of life [4]. One million neonatal deaths occur on their day of birth [5, 7]. Knowledge and practice of health care providers is essential in improving the survival of new-born and reduces neonatal mortality and morbidity [8].

\footnotetext{
*Correspondence: tesfaytsegay4@gmail.com

1 Department of Nursing, Adigrat University, Adigrat, Ethiopia

Full list of author information is available at the end of the article
}

In Ethiopia 37 neonates died per 1000 live births [9]. Similarly in Tigray region, there are 32,098 live births. Even though midwives are more likely to attend labour and provide new-born care, 3515 (11\%) neonates died at health facilities [10]. In Ethiopia specifically central zone of Tigray region health facilities there is no clear information regarding the knowledge and practice of midwives towards immediate newborn care. Therefore, it is crucial to assess the knowledge and practice of midwives towards immediate new-born care and provide well targeted intervention.

\section{Main text \\ Methods}

Institutional based cross-sectional study design was conducted from January to June, 2016 in central zone public health facilities of Tigray region. Central zone have 54 public health centers and 6 hospitals with 210 midwives working there.

A sample of 150 currently working midwives was included in the study. The sample size was determined using single population proportion formula. It was computed by considering $50 \%(\mathrm{p}=0.5)$ prevalence of knowledge and practice, $95 \% \mathrm{CI}$, and $5 \%$ margin of error. This 
resulted in 150 sample size after including $10 \%$ for nonresponse rate. Correction formula was used since the source population was less than the sampled population.

All public health facilities were included in the study. Final study subject was selected using convenience sampling method and midwives working in health facilities during the data collection time were included in the study.

Structured questionnaire was adapted with modification from different related literatures [1, 8, 11-13]. Observation checklist was adopted from save the children international [14]. The questionnaire and checklist were prepared first in English then translated to Tigrigna and retranslation to English. Questionnaire was pretested on $5 \%$ of the same source population other than the sampled population. Based on the pre-test, questions were revised, edited, and those found to be unclear or confusing were modified. Finally, structured closed ended Tigrigna version questionnaire was used for data collection. Moreover, checklist was used to assess immediate new care practice of the midwives.

Data was collected by face to face interview and nonparticipatory observations. Data collectors were five BSc midwives. They were trained for 2 days on the study instrument and data collection procedures. Additionally, two BSc Nurses, and assisted the data collectors.

\section{Operational definition}

Knowledge Refers to the knowledge response of midwives to the structured questions on the steps of newborn care, that is good knowledge when they respond correctly to $>75 \%$ of the knowledge questions ( $>8$ steps), fair knowledge respond to $51-74 \%$ (5-8 steps) and poor knowledge respond to $<50 \%$ ( $<5$ steps) of the 10 cares given to immediately born baby.

Practice Refers to the performance of midwives according to prepared checklist regarding new-born care. If the midwives performed the task at least $50 \%$ or above median (responded $>20$ questions) of the steps in the checklists was considered as practiced, and not practiced if performed $50 \%$ or below median $\leq 20$ questions) of the tasks in the checklists.

The collected data was entered into SPSS version 21.0. Variables with p-value less than 0.3 on bivariate analysis were entered into the multivariable analysis and adjusted odds ratio with $95 \%$ CI was used to ascertain the association between dependent and independent variables. The level of significance was taken at $\alpha<0.05$. Finally, result was presented in texts, and tables.

Ethical clearance and approval was obtained from research ethics committee of department of nursing and midwifery, Addis-Ababa University. Official cooperation letter was written from Tigray health bureau to each woreda health office and written permission was obtained from each respondents.

\section{Results \\ Participants' socio-demographic characteristics}

Totally 147 midwives were participated in the study which gives a response rate of $98 \%$. Among the respondents 88 (59.9\%) were from health center and 59 (40.1\%) from hospitals. One hundred seventeen $(79.6 \%)$ were females and 35 (23.8\%) of the participants were in the age group of 25-29. Orthodox Christianity was the dominant religion consisting of 135 (91.8\%). Majority (83.0\%) of the respondents were diploma, $55(37.4 \%)$ respondents had work experience of $1-5$ years and $49.7 \%$ were married.

\section{Participants knowledge on immediate newborn care}

Participants responded that the advantage of early initiation of breastfeeding; 97 (66\%) said, it prevents the

\begin{tabular}{llc}
$\begin{array}{l}\text { Table } 1 \text { Knowledge of } \\
\text { given to immediately born baby in central }\end{array}$ & $\begin{array}{c}\text { midwives } \\
\text { zone, Tigray, }\end{array}$ \\
Ethiopia, 2016 & & \\
\hline Variable & $\begin{array}{l}\text { Frequency } \\
(\mathrm{N}=147)\end{array}$ & Percent $(\%)$ \\
& &
\end{tabular}

Knowledge of midwives on advantage of skin-to-skin contact

$\begin{array}{lrr}\text { Prevent hypothermia } & 64 & 55.8 \\ \text { Help baby stay warm } & 84 & 57.1 \\ \text { Bonding } & 40 & 27.2 \\ \text { Help expel placenta and uterine } & 2 & 1.4 \\ \quad \text { contraction } & & \end{array}$

Knowledge of midwives on measures to be taken for baby unable to cry after delivery

$\begin{array}{lrr}\text { Suck the baby } & 136 & 92.5 \\ \text { Call a help and start resuscitation } & 105 & 71.4 \\ \text { Start cardio-pulmonary resuscitation } & 10 & 6.8 \\ \text { Kicking of the babies buttock } & 3 & 2.0 \\ \text { Oxygen administration } & 4 & 2.7\end{array}$

Knowledge on time of bathing for immediately born baby

$\begin{array}{lrr}\text { Before } 24 \text { h of delivery } & 9 & 6.1 \\ \text { After } 24 \text { h of delivery } & 110 & 74.8 \\ \text { I do not know } & 5 & 3.4 \\ \begin{array}{l}\text { Counsels mother to wash at home } \\ \text { after } 24 \mathrm{~h}\end{array} & 23 & 15.6\end{array}$

Knowledge on the importance of providing eye ointment $\begin{array}{lll}\text { Prevent eye infection } & 57 & 38.8\end{array}$ $\begin{array}{lll}\text { Prevent blindness } & 12 & 8.2\end{array}$ $\begin{array}{lll}\text { Prevent conjunctivitis } & 21 & 14.3\end{array}$ $\begin{array}{lll}\text { Prevent from STI } & 23 & 15.7\end{array}$ $\begin{array}{lll}\text { Prevent gonorrhoea } & 2 & 1.4\end{array}$ $\begin{array}{lll}\text { Prevent syphilis } & 8 & 5.5\end{array}$ $\begin{array}{lll}\text { As prophylaxis } & 8 & 5.5\end{array}$ Prevent dryness of eye $\quad 1 \quad 0.7$ 
newborn from hypoglycemia and 91 (61.9\%) of respondents know the advantage of colostrum on preventing new-born baby from infection. Among all, 137 (93.2\%) of respondents had knowledge on the appropriate time of initiation of breastfeeding for the newborn baby.

Most of the respondents know on placing the newborn on mother's abdomen $122(83 \%)$ immediately after delivery and 127 (86.4\%) of midwives had knowledge of providing TTC eye ointment on both eyes (Additional file 1 : Table S1). When the respondents asked about the immediate new-born complications, majority of them identified hypothermia, hypoxia and infection (Additional file 2: Table S2). Around 9 (6.15) of mothers wash babies before $24 \mathrm{~h}$ of delivery (Table 1 ).

The overall Knowledge of midwives on immediate newborn care was $17.7 \%, 57.1 \%$ and $25.2 \%$, good, fair and poor knowledge respectively.

\section{Participants practice of newborn care}

Around 146 (99.3\%) of respondents have prepared cord tie and clamp before delivery, but $98 \%$ of midwives did not prepared baby identification material (Table 2).
About 146 (99.3\%) of participants in this study were not practiced to put baby identification bands on the wrist and ankle after delivery. Majority of the respondents, 145 (98.6\%) have immediately dried the whole body of baby including the head and limbs but 14 (9.5\%) of respondents have not removed wet cloth used to dry the baby. Most 145 (98.6\%) of respondents were administered vitamin $\mathrm{K}$ to the new-born immediately.

Overall $52.4 \%$ of midwives practiced immediate newborn care appropriately.

\section{Factors associated with immediate newborn care}

Variables which have p-value less than or equal to 0.3 in Bivariate analysis were entered to multi-variable analysis. The multi-variable analysis result showed that work environment was significantly associated with practice of new-born care that is midwives working at health center were $82 \%$ lower odds of new-born care compared to those working in the hospitals (Table 3 ).

\section{Discussion}

According to this study even-though $85.7 \%$ of respondents had received in service training, participants had

Table 2 Practice of midwives on immediate newborn care in central zone, Tigray, Ethiopia, 2016

\begin{tabular}{|c|c|c|}
\hline Variable & Frequency $N=147$ & Percent (\%) \\
\hline \multicolumn{3}{|c|}{ Washes hands with soap and water, dried with a clean dry } \\
\hline Perform task completely & 36 & 24.5 \\
\hline Unable to perform task completely & 111 & 75.5 \\
\hline \multicolumn{3}{|c|}{ Wipes the eyes and face when the head is delivered } \\
\hline Perform task completely & 94 & 63.9 \\
\hline Unable to perform task completely & 53 & 36.1 \\
\hline \multicolumn{3}{|c|}{ Clean eyes immediately after birth with swab soaked in sterile water, using separate swab for each eye } \\
\hline Perform task completely & 44 & 29.9 \\
\hline Unable to perform task completely & 103 & 70.1 \\
\hline \multicolumn{3}{|c|}{ Delivery surface covered with sterile dry towel } \\
\hline Perform task completely & 135 & 91.8 \\
\hline Unable to perform task completely & 12 & 8.2 \\
\hline \multicolumn{3}{|c|}{ When baby not cried within 30 min of delivery, called help and prepared for steps of resuscitation } \\
\hline Perform task completely & 42 & 85.7 \\
\hline Unable to perform task completely & 7 & 14.3 \\
\hline \multicolumn{3}{|c|}{ Use appropriate size of mask for resuscitation } \\
\hline Perform task completely & 45 & 91.8 \\
\hline Unable to perform task completely & 4 & 8.2 \\
\hline \multicolumn{3}{|l|}{ Cord tie } \\
\hline Perform task completely & 84 & 57.1 \\
\hline Unable to perform task completely & 63 & 42.9 \\
\hline \multicolumn{3}{|c|}{ Cord cut with sterile scissor or surgical blade } \\
\hline Perform task completely & 99 & 67.3 \\
\hline Unable to perform task completely & 48 & 32.7 \\
\hline
\end{tabular}


Table 3 Multivariable analysis of variables with practice of newborn care, among midwives working in central zone, Tigray, Ethiopia, 2016

\begin{tabular}{|c|c|c|c|c|c|}
\hline \multirow[t]{2}{*}{ Variables } & \multicolumn{2}{|c|}{ Practiced new-born care } & \multirow[t]{2}{*}{ COR $(95 \% \mathrm{Cl})$} & \multirow[t]{2}{*}{ AOR $(95 \% \mathrm{Cl})$} & \multirow[t]{2}{*}{$p$-value } \\
\hline & Yes, n (\%) & No, n (\%) & & & \\
\hline \multicolumn{6}{|l|}{ Marital status } \\
\hline Single & $23(48.9 \%)$ & $24(51.1 \%)$ & 1 & 1 & \\
\hline Married & $48(65.8 \%)$ & $25(34.2 \%)$ & $2.00(0.94,4.23)$ & $1.90(0.79,4.58)$ & 0.15 \\
\hline Divorced & $2(16.7 \%)$ & $10(83.3 \%)$ & $0.20(0.04,1.05)$ & $0.22(0.04,1.26)$ & 0.09 \\
\hline Widowed & $4(26.7 \%)$ & $11(73.3 \%)$ & $0.38(0.10,1.36)$ & $0.40(0.09,1.73)$ & 0.22 \\
\hline \multicolumn{6}{|l|}{ Religion } \\
\hline Orthodox & $74(54.8 \%)$ & $61(45.2 \%)$ & 1 & 1 & 0.036 \\
\hline Muslim & $3(25.0 \%)$ & $9(75.0 \%)$ & $0.27(0.07,1.06)$ & $0.19(0.04,0.89)$ & \\
\hline \multicolumn{6}{|c|}{ Working environment } \\
\hline Hospital & $46(78.0 \%)$ & $13(22.0 \%)$ & 1 & 1 & 0.000 \\
\hline Health center & $31(35.2 \%)$ & $57(64.8 \%)$ & $0.15(0.07,0.32)$ & $0.18(0.07,0.43)$ & \\
\hline \multicolumn{6}{|c|}{ Educational status } \\
\hline Diploma & $60(49.2 \%)$ & $62(50.8 \%)$ & 1 & 1 & 0.87 \\
\hline Degree & $17(68.0 \%)$ & $8(32.0 \%)$ & $2.2(0.88,5.47)$ & $1.10(0.32,3.72)$ & \\
\hline \multicolumn{6}{|c|}{ Knowledge on newborn care } \\
\hline Fair & $43(51.2 \%)$ & $41(48.8 \%)$ & 1 & 1 & \\
\hline Good & $16(61.5 \%)$ & $10(38.5 \%)$ & $1.52(0.62,3.75)$ & $1.42(0.48,4.17)$ & 0.52 \\
\hline Poor & $18(48.6 \%)$ & $19(51.4 \%)$ & $0.90(0.42,1.96)$ & $1.3(0.51,3.33)$ & 0.57 \\
\hline \multicolumn{6}{|c|}{ Training on newborn care } \\
\hline Yes & $15(71.4 \%)$ & $6(28.6 \%)$ & 1 & 1 & 0.25 \\
\hline No & $62(49.2 \%)$ & $64(50.8 \%)$ & $0.38(0.14,1.06)$ & $0.48(0.14,1.65)$ & \\
\hline
\end{tabular}

poor knowledge regarding care of new-born at birth (25.2\%). This is in line with similar study done in Sudan [1]. This indicates that midwives in both study area have knowledge gap on immediate new-born care.

The knowledge of study participants on immediate new-born care of this survey were good (17.7\%), fair (57.1\%) and poor $(25.2 \%)$. This is relatively lower than study done in Egypt [8]. This might be related to the educational status of respondent's, there was presence of degree and speciality in the study done in Egypt.

About $99.3 \%$ of participants in this study were not practiced to put baby identification bands on the wrist and ankle after delivery. This is consistent with the study done in Khartoum, Sudan [1]. This will increases misshaping or exchange of babies in busy delivery room or time.

Practice of respondents towards immediate new-born care in this study were $52.4 \%$ which is relatively higher than the study done in Sudan [1]. This might be due to the descriptive statistics used at both study areas, that is the study done in Sudan had taken mean where as in this study practice was calculated from median.

This study result indicated that midwifes working at health center were $82 \%$ lower odds of new-born care compared to those working in the hospitals. This is different from the same study done by MAISHA program in Tanzania [12]. This might be due to difference in sociodemographic characteristics.

\section{Conclusion and recommendation}

Based on the finding midwives had knowledge and practice gap on immediate new-born care. Statistically significant difference of new-born care was observed among the midwives working in the health center and hospital. In-service training and capacity building of the midwives related to knowledge and skill on newborn care is crucial. Special focus should provide to include immediate newborn care on pre-service training curriculum at college level.

\section{Limitation}

Sampling procedure used for this study was convenience so it is limited to talk with this to the general population. The sample size used might not be enough to detect the statistical difference between the dependent and outcome variable. The nature of study design could not show seasonal variation and temporal relationship of cause and effect. Absence of similar literature in Ethiopia. 


\section{Additional files}

Additional file 1: Table S1. Knowledge on immediate newborn care of midwives at central zone Tigray region, Ethiopia, 2016

Additional file 2: Table S2. Knowledge of midwives on complication of immediately born baby and preventive methods at central zone, Tigray region, Ethiopia, 2016.

\section{Abbreviations}

Cl: confidence interval; SPSS: statistical package for social science.

\section{Acknowledgements}

We would like to acknowledge the Regional Health Bureau of Tigray and Central Zone Health Office for their cooperation in conducting this study. We are very grateful to the study participants for their willingness to participate in this study and to the field data collectors for their hard work and sincere contribution.

\section{Authors' contributions}

TTG carried out the conception and designing the study, performed statistical analysis and wrote the manuscript. AGA participated in the conception and designing the study, performed statistical analysis and wrote the manuscript. RM participated in designing the study, analysis, reviewing and editing the final draft and manuscript. MHG participated in the conception and designing the study, performed statistical analysis and wrote the manuscript. All authors read and approved the final manuscript.

\section{Funding}

Addis Ababa University. The funder has no role in the design, analysis and interpretation of the results.

\section{Availability of data and materials}

The datasets during and/or analyzed during the current study available from the corresponding author on reasonable request.

\section{Ethics approval and consent to participate}

Ethical clearance and approval was obtained from the research ethics committee of department of nursing and midwifery, college of health science, AddisAbaba University. Official cooperation letter was written from department of nursing and midwifery to Tigray regional health bureau. Then Tigray regional health bureau sent written cooperation letter to all of the district health bureaus of central zone and hospitals. Each district health bureaus wrote official letter to each health facilities under their control. Health facility managers gave written permission to the maternal and child health department head. After explaining about the purpose, and the possible benefit of the study; written permission was obtained from each respondents. Confidentiality of the respondent was maintained throughout the study.

\section{Consent for publication}

Not applicable for this section.

\section{Competing interests}

The authors declare that they have no competing interests.

\section{Author details}

${ }^{1}$ Department of Nursing, Adigrat University, Adigrat, Ethiopia. ${ }^{2}$ Department of Nursing, Addis Ababa University, Addis Ababa, Ethiopia. ${ }^{3}$ Department of Public health, Adigrat University, Adigrat, Ethiopia.

Received: 12 July 2019 Accepted: 31 July 2019

Published online: 06 August 2019

\section{References}

1. Nasor Taha FA. Assessment of knowledge, attitude and practices of nurse midwives towards immediate care of the newborn in Khartoum state teaching hospitals. J Am Sci. 2013;9(9):263.

2. Cunningham G, Leveno KJ, Bloom SL, Hauth JC, Gilstrap L III, Wenstrom KD. Williams obstetrics. 22nd ed. New York: McGraw-Hill; 2007.

3. WHO. Neonatal and perinatal mortality: country, regional and global estimates. Geneva: WHO; 2006

4. WHO. The world health report: make every mother and child count. Geneva: WHO; 2005 .

5. UNICEF. Progress report. Key finding committing to child survival: a promise renewed. 2014.

6. Federal Republic of Nigeria Ministry of Health. Saving newborn lives in Nigeria: newborn health in the context of the integrated maternal, newborn and child health strategy, revised. 2nd ed. Abija: Yaliam Press; 2011.

7. You D, Bastian P, Wu J, Wardlaw T. Levels and trends in child mortality: estimates developed by the UN inter-agency group for child mortality estimation. New York: United Nations Children's Fund UN Plaza; 2013.

8. El Fattah N, Nagwa A, El Dein Z. Assessment of quality of nursing care provided immediately after birth at University Hospital in El kom-Minoufiya, Egypt. Life Sci J. 2012;9(4):2115-26.

9. Central statistics Agency, ICF. Demographic and health survey preliminary report, Ethiopia. Addis Ababa: Central statistics Agency, ICF; 2011.

10. Federal Ministry of Health Policy Planning Directorate. Health and health related reports. Addis Ababa: Federal Ministry of Health; 2011.

11. Louis D, Kumar P, Gupta A. Practitioners' series knowledge and practices of healthcare providers about essential newborn care and resuscitation in a district of Haryana. J Indian Med Assoc. 2013;111(2):114-7.

12. Subbiah N, Sarin J, Jeeva S. Effectivenss of educational intervention on neonatal resuscitation among nursing personnel. Popul Perspect Issues. 2012;35(1):36-45.

13. MAISHA Program. MAISHA quality of maternal and new-born care study. Key findings: immediate essential new-born care and resuscitation, Tanzania. 2010-2012.

14. Deborah A, Diana B, Susan G, Phyllis L. Saving new-born lives care of the new-born training guide. Save the children federation. 2005.

\section{Publisher's Note}

Springer Nature remains neutral with regard to jurisdictional claims in published maps and institutional affiliations.

\footnotetext{
Ready to submit your research? Choose BMC and benefit from:

- fast, convenient online submission

- thorough peer review by experienced researchers in your field

- rapid publication on acceptance

- support for research data, including large and complex data types

- gold Open Access which fosters wider collaboration and increased citations

- maximum visibility for your research: over $100 \mathrm{M}$ website views per year
}

At BMC, research is always in progress.

Learn more biomedcentral.com/submissions 